\title{
AS CONCEPÇÕES DE PROFESSORES DO ENSINO FUNDAMENTAL II SOBRE A IDADE MÉDIA: UMA ANÁLISE SOB A ÓTICA DA EDUCAÇÃO HISTÓRICA
}

\author{
THE CONCEPTIONS OF TEACHERS OF FUNDAMENTAL TEACHING II ON THE \\ MIDDLE AGE: AN ANALYSIS UNDER THE OPTICS OF HISTORY EDUCATION
}

Max Lanio Martins Pina ${ }^{1}$ Janaína Bernardes Silva²

\begin{abstract}
RESUMO: As reflexões contidas neste artigo referem-se a uma investigação realizada com professores que atuam nos anos finais do Ensino Fundamental com a disciplina de História, cujo objetivo é analisar, e compreender, suas concepções em relação ao conceito de Idade Média que é ministrado nessa fase da educação básica. Além das percepções, busca-se o entendimento da relevância desse conteúdo, assim como a forma que ele é abordado, quais recursos ou linguagens são utilizados didaticamente para realizar seu ensino em sala de aula. Por fim, buscou-se investigar se os docentes acreditam na capacidade de compreensão dos estudantes em relação à temática medieval. Para realização da pesquisa contou-se com o auxílio dos conceitos e método utilizados na Educação Histórica, que consiste na aplicação de um instrumental de cognição situado em História, com a finalidade de se obter as narrativas dos professores para, em seguida, classificá-las em categorias visando sua compreensão. Neste sentido, foi aplicado um questionário contendo 5 questões, as quais foram respondidas por 13 professores vinculados à rede pública municipal de Porangatu, Goiás. A investigação se respaldou nos seguintes pesquisadores: Barca (2000a, 2000b, 2004, 2006, 2007a, 2007b, 2011, 2012), Germinari (2011), Castex (2008), Cainelli (2008, 2012), Saddi (2011), Rüsen (2001, 2007) e Silva (2011, 2012, 2014), os quais são expoentes da linha de investigação da Educação Histórica na Europa e no Brasil.
\end{abstract}

Palavras-chave: Concepções de Professores. Idade Média. Ideias Históricas. Educação Histórica.

ABSTRACT: The reflections in this article refer to an investigation carried out with teachers who work in the final years of Elementary School with the discipline of History, whose objective is to analyze and understand their conceptions in relation to the concept of the Middle Ages that is taught at this stage of education basic. In addition to the perceptions, we seek to understand the relevance of this content, as well as the form that it is approached, which resources or languages are used

1 Professor da Universidade Estadual de Goiás. Mestre em História pela Pontifícia Universidade Católica de Goiás.

2 Especialista em Educação e Linguagens pela Universidade Estadual de Goiás. Agente Administrativo Educacional da Prefeitura Municipal de Porangatu. 
didactically to carry out teaching in the classroom. Finally, we sought to investigate whether teachers believe in students' ability to understand the medieval themes. For the accomplishment of the research it was counted on the aid of the concepts and the method used in History Education, which consists in the application of an instrument of cognition situated in history, with the purpose of obtaining the narratives of the teachers and then classifying them in categories for their understanding. In this sense, a questionnaire was applied containing 5 questions, which were answered by 13 teachers linked to the municipal public network of Porangatu, Goiás. The research was supported by the following researchers: Barca (2000a, 2000b, 2004, 2006, 2007a, 2007b, 2011, 2012), Germinari (2011), Castex (2008), Cainelli (2008, 2012), Saddi (2011), Rüsen $(2001,2007)$ and Silva $(2011,2012,2014)$, Who are exponents of the research line of History Education in Europe and Brazil.

Keywords: Conceptions of Teachers. Middle Ages. Historical Ideas. History Education.

\section{Introdução}

A Idade Média está em alta, pois se tornou um modismo na cultura contemporânea. Esta situação contribuiu para o surgimento, nas últimas décadas, de uma volumosa quantidade de livros, filmes, séries de televisão, e jogos eletrônicos, inspirados nas temáticas medievais. Assim, existe na atualidade uma cultura histórica, em torno desse período, que é alimentada pelo mercado cultural e pela indústria do entretenimento, fazendo com que o mundo medieval fique constantemente em evidência.

Ressalta-se a importância e a necessidade de compreensão das percepções e concepções que os professores possuem sobre esse período histórico, pois recentemente a proposta do MEC ao apresentar uma Base Nacional Comum Curricular - BNCC, no seu primeiro texto, gerou várias polêmicas quando se constatou que o ensino de História não contemplava, e ainda excluía, a Antiguidade e a Idade Média dos conteúdos obrigatórios a serem ensinados na educação básica (PINA, 2016b). Faz-se necessário, num momento como este, compreender como os profissionais, envolvidos com tais conteúdos, avaliam a importância desses períodos históricos para formação dos estudantes brasileiros e como eles são tratados em sala de aula.

Neste sentido, os autores entendem que a Idade Média se configura tanto como conceito quanto como conteúdo necessário para compreensão dos processos históricos que envolveram a história da humanidade e suas transformações ou permanências no tempo. Até o presente momento o modelo 
de currículo mínimo adotado para o ensino de História no Brasil privilegiou o período medieval, por adotar a forma quadripartite francesa para marcar e demarcar o tempo. Desta maneira, a Idade Média que é ensinada nas escolas brasileiras, se configura como um conceito e como um período histórico, que é considerado importante para construção do mundo contemporâneo e ocidental.

A conceituação cognitiva da Idade Média é de suma importância para os professores, bem como para os estudantes, pois permite a estes últimos entenderem que a atual realidade social, política, econômica, cultural, e religiosa do mundo, é uma criação humana e não uma entidade abstrata da qual se deve seguir cegamente. A História é um processo que está constituído por vários acontecimentos. Conhecê-los são necessários, pois permitem a construção de uma consciência crítica em relação à vida prática ${ }^{3}$ no presente e também para se perspectivar um futuro que possa garantir a possibilidade de transformação da realidade social.

\section{Pressupostos teóricos e metodológicos}

A Educação Histórica é compreendida como uma linha de investigação que surgiu na Inglaterra nos anos 1970 e 1980 para resolver uma problemática específica do ensino da disciplina de História no Reino Unido. Naquele período, o ensino permitia aos alunos escolherem qual disciplina cursar e, assim, os professores e historiadores perceberam que as aulas de História permaneciam vazias, enquanto as de Matemática estavam sempre lotadas de alunos. Esta situação gerou preocupações e incertezas para o futuro dos professores de História naquela nação. Foi observando o trabalho, e as pesquisas, de um grupo de professores da área da Educação Matemática, que os historiadores se lançaram na aventura das investigações em cognição histórica ${ }^{4}$. A princípio, as investigações dos historiadores ingleses visavam descobrir, e compreender,

\footnotetext{
3 Vida prática é entendida, nesse caso, como "mundo vital" ou "mundo da vida", termo que Rüsen extraiu de E. Husserl. Isto significa que tudo que está relacionado à existência do indivíduo refere-se à sua vida prática. (RÜSEN, 2001, p. 57).

4 Expressão utilizada para referir-se a forma como a mente humana processa cognitivamente as informações sobre o passado e as transforma, em seguida, em narrativas históricas.
} 
como os alunos formulavam cognitivamente o pensamento histórico a partir do mundo da vida prática (PINA, 2016a).

Assim, as reflexões desses intelectuais foram ampliadas para outras preocupações. Por isso o movimento britânico produziu uma série de resultados que justificou o deslocamento para as ideias históricas ${ }^{5}$ de crianças, adolescentes e jovens, em situação escolar, visando à compreensão das interpretações ou percepções destes quanto a: explicação histórica, empatia histórica, imaginação histórica, evidência histórica, significância histórica, mudança histórica, narrativa histórica e variância da narrativa histórica (PINA, 2016a). Deste modo, surgiu essa área de conhecimento que passou a ser conhecida tanto como linha de investigação, quanto como metodologia a ser empregada para investigar o ensino e a aprendizagem histórica.

Esse novo campo de conhecimento não poderia ser enquadrado nas Ciências da Educação, por isso os historiadores ingleses buscaram amparo na própria epistemologia da História para consolidar e validar suas reflexões, o que permitiu um diálogo bem aproximado com a Didática e a Teoria da História (GERMINARI, 2011). Neste sentido, a presente pesquisa se abrigou nessa linha de investigação por acreditar que ela oferece elementos, e recursos, para alcançar as percepções, visões e ideias dos professores sobre os conteúdos históricos ensinados por eles no cotidiano escolar.

Reconhece-se, portanto, que a Educação Histórica possui uma metodologia própria baseada nas três operações processuais da pesquisa histórica sugeridas por Rüsen (2007), as quais consistem de etapas como a heurística, seguida pela crítica, e finalizando com a interpretação dos dados obtidos das/nas fontes. Ela se apropriou dessas etapas para elaboração e aplicação do instrumental de pesquisa, que permite a crítica, bem como a interpretação das informações encontradas nas narrativas por meio de uma observação que demanda um esforço hermenêutico, sem o qual não seria possível uma análise para além daquilo que está dado nas fontes (SADDI, 2011).

\footnotetext{
${ }^{5}$ Essa expressão é utilizada para designar a forma como os indivíduos/sujeitos apresentam, em suas narrativas, suas concepções ou interpretações sobre o passado transformado em História. Tal expressão é encontrada nos trabalhos de Saddi (2011), Castex (2008), Germinari (2011) e Barca (2012).
} 
O instrumental de cognição histórica consistiu na aplicação de um questionário confeccionado pelos investigadores, que visava à produção das narrativas históricas ${ }^{6}$ dos professores dos anos finais do Ensino Fundamental da rede pública do município de Porangatu, Goiás, localizado às margens da Rodovia BR 153, distante $430 \mathrm{~km}$ da capital na direção ao norte, fazendo assim fronteira com o Estado do Tocantins.

Aplicou-se um total de 13 questionários respondidos por docentes que atuam em sala de aula com a disciplina de História, possuem entre 5 a 25 anos de experiência no magistério, e estão enquadrados numa faixa etária que vai dos 34 aos 53 anos de idade. Ao observar os anos de formação e a faixa etária dos professores envolvidos na pesquisa, pode-se afirmar que o grupo possui maturidade, bem como experiências, para apresentar respostas que permitam uma análise de como a Idade Média é entendida e ensinada na escola básica brasileira. Parte do grupo da amostra formou-se na antiga Faculdade de Educação, Ciências e Letras de Porangatu - FECELP - e a outra na mesma instituição, só que agora com a denominação de Universidade Estadual de Goiás - UEG, Campus Porangatu7. Os participantes da amostragem não serão distinguidos quanto ao gênero e serão tratados, e apresentados, como Professor $1,2,3$, sucessivamente. Adotou-se esta nomenclatura apenas para facilitar a redação do texto.

As narrativas foram analisadas e, em seguida, categorizadas, na intenção de serem compreendidas à luz da epistemologia da História, conforme sugere Silva (2014) e Saddi (2011). O instrumental possuía cinco questões, enumeradas de 1 a 5, que tinham como finalidades: alcançar as concepções sobre a Idade Média; compreender a relevância desse conceito; saber quais os recursos didáticos que são empregados para o seu ensino; e quais os temas medievais são mais abordados. Entendeu-se, nesta análise, ser importante saber se os professores acreditam que os alunos dos anos finais do Ensino Fundamental

${ }^{6}$ Constituem-se como narrativas históricas as respostas dos professores coletadas a partir do instrumental aplicado a eles em ambiente escolar.

${ }^{7}$ A Universidade Estadual de Goiás (UEG) foi criada no dia 14 de abril de 1999 e absorveu todas as faculdades estaduais isoladas existentes nas cidades do interior do Estado de Goiás. 
conseguem compreender os conteúdos sobre a Idade Média. Os resultados da pesquisa serão apresentados e discutidos no item a seguir.

\section{Resultados e discussão}

A investigação analisa, e estabelece, categorias para as 13 narrativas obtidas com a aplicação do instrumental que, de acordo com sua primeira questão, buscava averiguar como os professores dos anos finais do Ensino Fundamental conceituam o período Medieval. Conforme a historiadora portuguesa Barca (2012), é necessário alcançar as ideias prévias sobre um conceito substantivo ${ }^{8}$ em História por meio da classificação das respostas apresentadas nas narrativas realizadas em contexto escolar.

Para o historiador e pesquisador alemão Rüsen (2007, p. 93), as categorias históricas "designam contextos temporais gerais de estados de coisas com base nos quais estes aparecem como históricos". Neste sentido, elas "não se referem diretamente a nenhum estado de coisas, mas estabelecem a qualidade histórica da mudança temporal dos estados de coisas", que segundo o autor, na maioria das vezes não estão nas fontes, mas na atividade cognitiva dos historiadores. Consequentemente, as categorias são tipos ideais, abstrações, que servem ao pesquisador como recurso para classificar na intenção de compreender as informações e os elementos presentes nas fontes analisadas.

Antes de seguir com a análise das narrativas, não se pode omitir um fato delicado que esta verificação se deparou, pois constatou-se que ao menos três dos professores participantes da amostra reproduziram suas respostas e não mencionaram os créditos das fontes, o que configura plágio. Entendeu-se que esta situação não implicou nos resultados da pesquisa, pois as narrativas apresentadas pelos participantes refletem o seu ponto de vista, já que eles as selecionaram antes de apresentá-las como respostas pessoais. De fato, este não

\footnotetext{
8 "Os conceitos substantivos são conceitos historicamente construídos e atribuem significados específicos a determinados acontecimentos ocorridos em determinados espaços. Esses conceitos quando solicitados pelo historiador estão carregados de significado, desta forma o historiador pode utilizá-los sem a necessidade de maiores aprofundamentos, a menos no momento em que são construídos e assimilados pelos alunos, são os conceitos que garantem substância a aprendizagem histórica". (SANCHES; SCHMIDT, 2013, p. 283).
} 
é o melhor caminho e implica uma questão moral de desonestidade intelectual ${ }^{9}$. Todavia, essa realidade reflete duas questões. Primeiro, considera-se que esses docentes não levaram a sério a pesquisa, por isso preferiram escolher esse viés para preencher o questionário. Segundo, tais profissionais não se sentiram confiantes a ponto de narrar sobre um conteúdo que eles ministram no cotidiano escolar. Este último permite ponderar que existe uma falta de propriedade intelectual, em relação a determinados temas substantivos em História, o que ocasiona dificuldade em conceituá-los. Se o professor encontra dificuldades intelectuais para apresentar a si um conceito histórico, mais ainda terá para auxiliar, e orientar, seus alunos quanto à construção desses conceitos.

Ao considerar os dados, observou-se que os professores apresentaram quatro formas de concepção sobre a Idade Média. Vale ressaltar que as narrativas podem ser classificadas em mais de uma categoria, deste modo optou-se por relacioná-las naquelas em que as características mais se enquadram, ou mais se aproximam, das ideias centrais que estão estabelecidas como referências para se realizar as categorizações.

A primeira concepção denominou-se Tradicional, porque para esta perspectiva levou-se em consideração que as narrativas dos professores se assemelham à descrição conceitual contida no livro didático ou em outras fontes utilizadas para o ensino em sala de aula. Nesta perspectiva, entendeu-se que os docentes atuam como reprodutores desse conhecimento, pois a Idade Média não foi problematizada por meio de sua resposta, apenas descrita, segundo pode ser observado nas falas dos Professores 2, 3, 4, 10 e 12:

Período da história europeia que se inicia com a desintegração do Império Romano do Ocidente, com a chegada dos povos germânicos, a consolidação do feudalismo e a expansão do cristianismo, chegando ao fim no século XV. (PROFESSOR 2).

A Idade Média também foi conhecida como período medieval que corresponde ao período da história europeia que se inicia com a desintegração do Império Romano do Ocidente. A Idade Média

\footnotetext{
${ }^{9}$ A expressão "desonestidade intelectual" é utilizada por Moraes (2004) para designar o desdém moral da sociedade brasileira frente a reprodução de material intelectual sem respeitar o autor, ocasionando, assim, uma conduta de má fé do plagiário. Para o autor isso ocorre constantemente em todos os níveis educacionais no Brasil, não é só porque representa um habito imoral, mas o desconhecimento sobre Direito Autoral potencializa esse desrespeito ao criador intelectual.
} 
teve início com as invasões germânicas no século $V$, sobre o Império Romano do Ocidente. A Idade Média caracteriza pela economia ruralizada, enfraquecimento comercial, supremacia da Igreja Católica, sistema de produção feudal e sociedade hierarquizada. (PROFESSOR 3).

A Idade Média é um período da história entre os séculos $V$ e XV. Conhecida por algumas correntes como sendo a "Idade das Trevas", e por outras correntes como sendo uma época de grandes acontecimentos que moldaram a humanidade. Foi um período de inúmeras invasões territoriais, frequentes guerras e ampla intervenção da Igreja. Na sociedade praticamente não havia mobilidade social, a nobreza feudal era detentora de terras e arrecadava impostos. O clero tinha grande poder, pois era responsável pela proteção espiritual da sociedade. (PROFESSOR 4).

Também conhecida como período medieval, corresponde ao período da história europeia que se inicia com desintegração do Império Romano do Ocidente e que finda no século $X V$. As principais características da Idade [Média] foram a chegada dos povos bárbaros a consolidação do feudalismo e a expansão do cristianismo. (PROFESSOR 10).

Conhecida como Período Medieval, corresponde ao período da história europeia que se inicia com a desintegração do Império Romano do Ocidente e que finda no século XV. As principais características da Idade [Média] foram à chegada dos povos bárbaros, a consolidação do feudalismo e a expansão do cristianismo. (PROFESSOR 12).

Para a segunda categoria observou-se que a concepção sobre o período medieval foi Evasiva, porque nesta perspectiva percebeu-se que a construção narrativa dos professores não levou em consideração a preocupação em explicar detalhadamente a Idade Média. Eles optaram por elencar poucos aspectos desse período. Desta maneira, o conhecimento apresentado sobre o período está fragmentado, não permitindo uma visão da longa duração que o mesmo representa e nem das distintas sociedades que abrigou. Esta ideia pode ser observada nas citações dos professores 1, 9, 11 e 13:

Uma idade de prosperidade, distamento sociais, privilegiados e não privilegiados, que é a grande maioria, e alienação mental. (PROFESSOR 1).

Idade da prosperidade. Intervenção da Igreja. Invasões. Guerras. (PROFESSOR 9). 
Modo de produção feudal. Culturas teocêntricas. Relações de suserania e vassalagem. (PROFESSOR 11).

A Idade Média, também conhecida como Período Medieval, corresponde ao momento da história europeia que se inicia com a desintegração do Império Romano do Ocidente e que finda no século XV. (PROFESSOR 13).

No caso da terceira concepção, entendeu-se que a visão sobre a Idade Média foi Pessimista, porque nessa perspectiva levou-se em consideração que a narrativa apresenta a Idade Média como um passado considerado inferiorizado. Sendo assim, foram apresentadas, narrativamente, somente características negativas sobre o período medieval. Nesse caso, essas características permitem aos sujeitos uma consciência de que tudo que está relacionado a este período não tem valor histórico. Este aspecto está subentendido na resposta do professor 7:

A Idade Média se inicia com a ruralização, quem morava na cidade voltam aos feudos em busca de proteção e é com essa nova organização política, social e econômica que se inicia o fim do Império Romano. Idade marcada pela descentralização do poder, vários senhores feudais, sociedade dividida em clero, nobreza e cavaleiros, e por último os servos. Economia de subsistência, rara mobilidade social, onde somente a nobreza pertence o clero. (PROFESSOR 7).

A quarta, e última, categoria refere-se a uma concepção Otimista do medieval, em razão de que nesta perspectiva levou-se em consideração que as narrativas apresentam uma Idade Média com contribuições para a História da humanidade. Os docentes compreendem que o período medieval coopera de forma positiva para construção, bem como para as transformações que permitiram o surgimento do mundo ocidental. Esse otimismo é encontrado nas narrativas dos professores 5, 6 e 8 :

É importante esclarecer aos alunos que a Idade Média não foi só "longa noite dos mil anos" e Idade das Trevas. A civilização europeia medieval também realizou importantes descobertas e desenvolveu técnicas que propiciaram a expansão da agricultura, do sistema financeiro, da educação e das navegações. (PROFESSOR 5).

Um período da História da Europa entre os séculos $V$ e XV. Para alguns historiadores um período sem muitas relevâncias para a História dos seres humanos. Vejo a Idade Média como um período 
intermediário da História que teve sua importância, principalmente nas questões religiosas, nas inovações técnicas e agrícolas. [...] $O$ ensino sobre a Idade Média para os alunos do Ensino Fundamenta II, vai ajudar de alguma forma a compreensão dos outros períodos históricos [...]. (PROFESSOR 6).

[...] Podemos considerar esse período como uma fase de transição, época de dificuldades e inseguranças para toda Europa Ocidental. Vale ressaltar que o mesmo foi essencial para o surgimento da civilização moderna, com suas novas ideias e princípios mudando o mundo. [...] É de suma importância [para] os alunos do Ensino Fundamental II conhecer a Idade Média, porque a História é memória da preservação e da recordação do passado. (PROFESSOR 8).

Conforme as categorias descritas acima, observa-se que os docentes possuem uma multiplicidade de propostas explicativas ${ }^{10}$ para o conceito de Idade Média, indicando, assim, a existência de várias concepções referentes a esse conteúdo. Tais variações das respostas podem ser entendidas de muitas maneiras. Porém, ressalta-se que os dados obtidos com a investigação não possibilitaram uma interpretação que permita assegurar quais motivos concretos levam a essa multiplicidade. Nesse caso, a intenção deste trabalho não é julgar se os professores sabem ou distinguem acertadamente sobre a Idade Média, mas, conforme sugeriu Bloch (2001), compreender como são suas visões e interpretações sobre este período.

Por conseguinte, serão apresentadas ponderações sobre os motivos que levam a essas múltiplas concepções. Em primeiro lugar, destaca-se que a formação acadêmica de cada professor foi diferente, dado o contexto de objetivos adotados para o ensino de História no Brasil, conforme demonstrado nas características que representam o tempo de atuação/experiência do grupo que forma a amostragem dessa investigação. Esta situação demonstra que o ensino de História, nos últimos vinte anos, passou por consideráveis transformações, o que reflete na dificuldade, inexistência ou deficiência de uma formação continuada que atenda as exigências dessas mudanças. Também questiona-se a função/papel da universidade junto à educação básica na

\footnotetext{
10 De acordo com Barca (2000a, p. 29) essa multiplicidade de respostas faz parte da natureza do conhecimento histórico, conferindo assim, um caráter de provisoriedade a tais respostas. Isso significa que é possível se ter em relação a determinado assunto histórico vários tipos de concepções ou ideias, pois se considera na atualidade que em qualquer ciência, todas as teorias são provisórias.
} 
divulgação das novas modalidades do ensino de História, bem como na difusão das novas teorias que são produzidas em larga escala pelos historiadores.

A segunda questão do instrumental aplicado buscava averiguar se os professores da rede pública municipal acreditam existir alguma relevância para o aluno do Ensino Fundamental conhecer a Idade Média. Dentre os investigados, $77 \%$ conferem que há relevância para os alunos compreenderem a Idade Média, $15 \%$ apresentaram imprecisão na sua narrativa, e apenas $8 \%$ acreditam não ser relevante o ensino deste conceito/conteúdo na formação dos estudantes de nível fundamental (ver gráfico 1 ).

\section{Gráfico 1- Relevância da Idade Média para o Ensino Fundamental II}

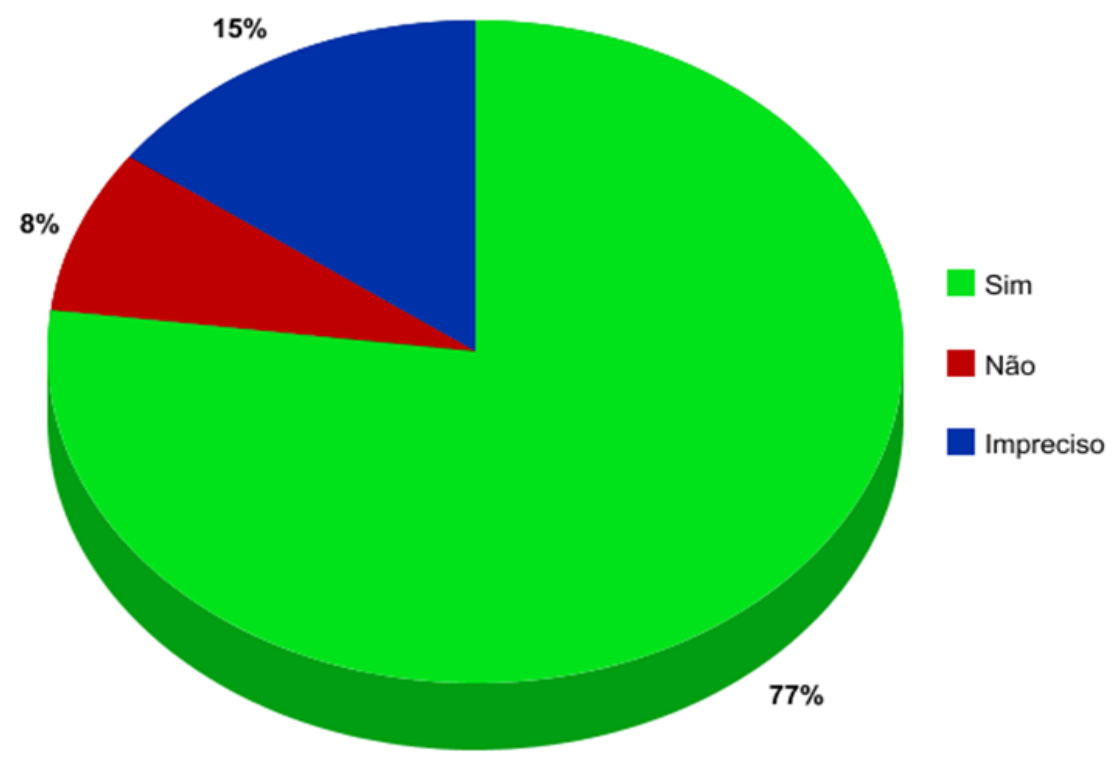

Fonte: os autores.

O Professor 13 concorda que se deve ministrar o conteúdo da Idade Média para o Ensino Fundamental por ser necessário compreender que as instituições existentes no mundo moderno foram gestadas nesse período. Para ele, falar desse momento histórico é

[...] de certa forma, falar de nós mesmos. Ela representa o longo período de gestação no qual foi criado o mundo moderno: as atuais nações europeias, das quais derivamos, juntamente com suas respectivas línguas e literaturas, são partes do legado 
medieval. Nosso quotidiano está repleto de inovações surgidas naquela época, como as universidades, os bancos, e ainda a imprensa, o relógio mecânico e os óculos. Devemos a Idade Média inclusive a origem dos modernos sistemas de representação política e os fundamentos da mentalidade cientifica que caracterizam a civilização ocidental. (PROFESSOR 13).

Para o Professor 7 não é relevante o ensino desse conteúdo para essa fase da educação. Salienta-se que o mesmo foi classificado como pessimista na sua conceituação sobre a Idade Média. Seu ponto de vista está de acordo com a sugestão do primeiro texto proposto para o currículo de História da BNCC, que excluía a Idade Média de ser ensinada na sala de aula. Para este professor é um grande desafio explicar a noção de tempo histórico para essa fase do ensino, porque na sua concepção os estudantes não conseguem relacioná-lo com sua vida prática:

A Nova Base Comum Curricular retirou a Idade Média do currículo a ser estudado nas escolas públicas. Eu concordo com essa atitude, [pois] esse período da Idade Média está muito distante da realidade do aluno, o que faz o professor não conseguir torná-lo significativo, sendo muito importante [...] fazer um paralelo com a realidade para que o mesmo possa apresentar um aprendizado de qualidade. (PROFESSOR 7).

No caso do Professor 12, sua resposta não se apresentou objetiva quanto à relevância do período medieval para os adolescentes, e o mesmo divagou pelos novos desafios enfrentados pelo ensino na era da informação e da incorporação de novas abordagens historiográficas:

O ensino da História tem apresentado grandes desafios aos professores, que exigem novas posturas no ambiente escolar e na sociedade. Numa sociedade informacional, esses desafios são imensos, e o papel do educador ganha centralidade no processo de construção da autonomia das crianças e dos jovens. Esse esforço incorpora ao ensino de história novas abordagens historiográficas e contribuições de outras áreas, como sociologia, a Semiótica, a Antropologia e a linguística entre outras. (PROFESSOR 12).

O que se constata, conforme foi demonstrado no gráfico 1, é o fato de que a maioria dos investigados demonstraram ser otimistas quanto à importância do ensino da Idade Média para os anos finais do Ensino Fundamental. Diante disso, pode-se afirmar que o primeiro texto da BNCC, denominado como provisório, 
não representava todos os professores do Brasil, mas as ideias de uma parcela de historiadores que acusam ser o ensino deste período, eurocêntrico. A crítica ao eurocentrismo é pertinente, todavia não se deve descartar um período da História por acreditar que ele não se relaciona com a vida prática presente ou só faz menção da história da Europa. De acordo com o que foi demonstrado no início deste artigo, os temas medievais fazem parte da cultura contemporânea, basta observar o cinema, as séries de televisão, os jogos eletrônicos, e os livros inspirados e ambientados nesse período, que estão presentes no cotidiano dos alunos brasileiros.

Em seguida o instrumental esperava descobrir quais os recursos, fontes e linguagens que, além do livro didático, são utilizados para ensinar a História Medieval. Partiu-se do pressuposto de que todos os docentes fazem uso cotidiano do manual didático em suas aulas, deste modo procurou-se, com essa questão, averiguar se outras soluções ou ferramentas também são empregadas para o ensino da medievalidade. O resultado confirmou o uso cotidiano do livro didático por todos os participantes, assim demonstrou existir uma predileção dos professores pelos recursos midiáticos como o vídeo, os filmes e os documentários, conforme pode ser averiguado nas citações a seguir, e também no quadro 1 :

Utilizamos data show, filmes, documentários. Para facilitar o entendimento dos alunos. Temos o laboratório de informática. (PROFESSOR 2).

Data show, documentários, filmes e vídeos. Para que o aluno tenha uma aula diferenciada e mais facilidade para compreender e entender o conteúdo. (PROFESSOR 3).

Documentários, filmes, outras fontes bibliográficas. (PROFESSOR 9).

Filmes, documentários, Power point e animações. Esses recursos são utilizados para que as aulas fiquem mais atrativas e chamem a atenção dos alunos, melhorando assim a sua concentração a memorização do conteúdo. (PROFESSOR 13).

Ressalta-se não ser possível, para esta investigação, compreender as formas reais de como esses recursos midiáticos são manuseados, e nem em quais perspectivas são inseridos didaticamente no cotidiano das aulas de 
História. O instrumental aplicado não permite o alcance dessas informações, o que torna esse assunto um problema a ser investigado em outro momento.

Entende-se que os recursos didáticos têm como objetivo aumentar o potencial de alcance da mensagem transmitida pelo professor, sendo capaz de estimular os mecanismos sensoriais e audiovisuais. No mundo globalizado e cada vez mais conectado, está se tornando difícil educar, e ensinar, sem o uso das novas tecnologias, situação que tem forçado a inserção de novos mecanismos como ferramentas didático-pedagógicas no cotidiano escolar. Porém, é importante lembrar que o professor deve possuir autonomia e propriedade intelectual sobre qualquer conteúdo/tema a ser explorado, utilizando os recursos e as novas tecnologias apenas como auxiliares no processo de ensinoaprendizagem.

Segue, abaixo, o quadro 1 contendo a lista dos recursos, materiais e novas tecnologias descritos pelos professores como ferramentas que auxiliam em suas aulas para o ensino da Idade Média.

Quadro 1- Recursos, instrumentos e linguagens utilizados para o ensino de história

\begin{tabular}{|c|c|}
\hline DESCRIÇÃo DoS RECURSOS & QUANTIDADE DE VEZES CITADOS \\
\hline 1.Livro didático. & 13 \\
\hline 2.Vídeos, filmes e documentários. & 13 \\
\hline $\begin{array}{c}\text { 3.Projetor, Slides, Power Point e } \\
\text { animações. }\end{array}$ & 05 \\
\hline 4.Revistas e reportagens. & 03 \\
\hline $\begin{array}{c}\text { 5.Fontes históricas e fontes } \\
\text { bibliográficas. }\end{array}$ & 02 \\
\hline 6.Imagens e ilustrações. & 02 \\
\hline 7.Internet e sites. & 02 \\
\hline 8.Maquete. & 02 \\
\hline 9.Pintura. & 01 \\
\hline 10.Pesquisa de campo. & 01 \\
\hline 11.Gincana. & 01 \\
\hline 12.Trabalho em grupo. & 01 \\
\hline 13.Quadro digital. & 01 \\
\hline 14.Teatro. & 01 \\
\hline
\end{tabular}

\section{Fonte: os autores.}

Outra situação que chamou a atenção foi perceber que em plena era da informação a internet/site só foi mencionada duas vezes (ver quadro 1), isto é, somente dois professores declararam fazer uso dessa linguagem para o ensino 
de Medieval, como foi aludido pelo Professor 5, o qual afirma que "com a chegada da tecnologia a internet se tornou a grande aliada do trabalho docente", contudo, para este grupo, isso ainda não se tornou realidade.

Percebe-se, nessa situação, que a maioria dos participantes da pesquisa ainda sente dificuldades em manusear as tecnologias e suas linguagens no que compete à sua incorporação ao cotidiano escolar e no ensino de História. Talvez essa dificuldade possa estar relacionada às condições de trabalho desse profissional. Será que a escola possui acesso a à rede mundial de computadores? Será que esse professor possui acesso à internet? Os laboratórios da escola possuem equipamentos suficientes para a demanda de alunos? São equipamentos novos ou defasados? A realidade da escola pública no Brasil permite aulas com uso de tecnologias? A internet disponível possui um sinal de qualidade? Essas são questões que a pesquisa não conseguiu atingir, dada sua preocupação inicial - os conceitos produzidos sobre o período medieval pelos professores - mas devem ser levadas em conta diante de um resultado como estes aqui apresentados.

$\mathrm{Na}$ sequência da investigação, os professores deveriam elencar os conteúdos da Idade Média que mais possuem predileção por ensinar. O Feudalismo foi citado por 5 vezes, já as Cruzadas e a Peste Negra foram lembradas por 3 professores, a Cidade conferiu 2 citações. Outras 17 palavras/temas foram mencionadas apenas uma única vez pelos docentes, conforme pode ser conferido no quadro 2.

Essa diversidade de temas pressupõe que não há um único assunto sobre o período medieval que desperte nos educadores uma predileção, mas que, de modo geral, tudo que está relacionado a este período histórico é importante, e necessita ser ensinado e discutido com os alunos.

Quadro 2- Conteúdos medievais que os professores gostam de ensinar

\begin{tabular}{|c|c|}
\hline TEMAS/ASSUNTOS & QUANTIDADE DE VEZES CITADOS \\
\hline 1.Feudalismo & 05 \\
\hline 2.Cruzadas & 03 \\
\hline 3.Peste Negra & 03 \\
\hline 4.Cidade & 02 \\
\hline 5.Campo & 01 \\
\hline 6.Política & 01 \\
\hline 7.Poder & 01 \\
\hline
\end{tabular}




\begin{tabular}{|c|c|}
\hline 8.Educação & 01 \\
\hline 9.Cultura & 01 \\
\hline 10.Arte & 01 \\
\hline 11.Igreja & 01 \\
\hline 12.Cristianismo & 01 \\
\hline 13.Religião & 01 \\
\hline 14.Sociedade & 01 \\
\hline 15.Relações servis & 01 \\
\hline 16.Arquitetura & 01 \\
\hline 17.Economia & 01 \\
\hline 19.Reino Franco & 01 \\
\hline 20.Literatura medieval & 01 \\
\hline 21. Sem preferência & 01 \\
\hline 22.Comparar com o & 01 \\
presente. & \\
\hline
\end{tabular}

Fonte: os autores.

Não se pode deixar de frisar que o Professor 13, ao mencionar a literatura como um dos assuntos pelo qual tem preferência em abordar nas suas aulas, fez uma relação entre passado e presente, quando compara o cordel com elementos existentes na literatura Medieval.

Tal citação reforça a ideia de que nem sempre é preciso utilizar somente elementos eurocêntricos, e fora da realidade dos estudantes, para se ensinar a Idade Média. Em Goiás existem aspectos culturais presentes no cotidiano, ou na vida prática dos estudantes, que podem, e devem, ser incorporados, e explorados, enquanto fontes para a aprendizagem dos assuntos desse período como, por exemplo: a vida religiosa com a presença da Igreja Católica, que em seus templos ainda badalam o sino para marcar o tempo e indicar os horários das missas; a existência dos feriados, que apontam os dias santos; as procissões, que fazem parte da vida cristã católica; as Cavalhadas, que acontecem em algumas cidades goianas, e representam as lutas entre mouros e cristãos; entre outros.

Por fim, a investigação intenciona saber se os professores acreditam que os alunos dos anos finais do Ensino Fundamental conseguem compreender os conteúdos sobre a Idade Média. Em vista disso, notou-se que a maioria dos professores acredita que o estudo da Idade Média, e sua compreensão, contribuem e são relevantes na formação dos estudantes, pois despertam sua imaginação, bem como auxiliam na construção das identidades individuais e, também, sociais. Assim sendo, eles concordam que, nessa fase da educação 
básica, os estudantes conseguem alcançar a assimilação do período histórico em questão. Somente um professor afirmou não acreditar na possibilidade de entendimento, e apreensão, dos conteúdos medievais, por parte dos escolares desse nível de educação, conforme demonstrado no gráfico 2.

\section{Gráfico 2- Professores que acreditam que os alunos compreendem a Idade Média}

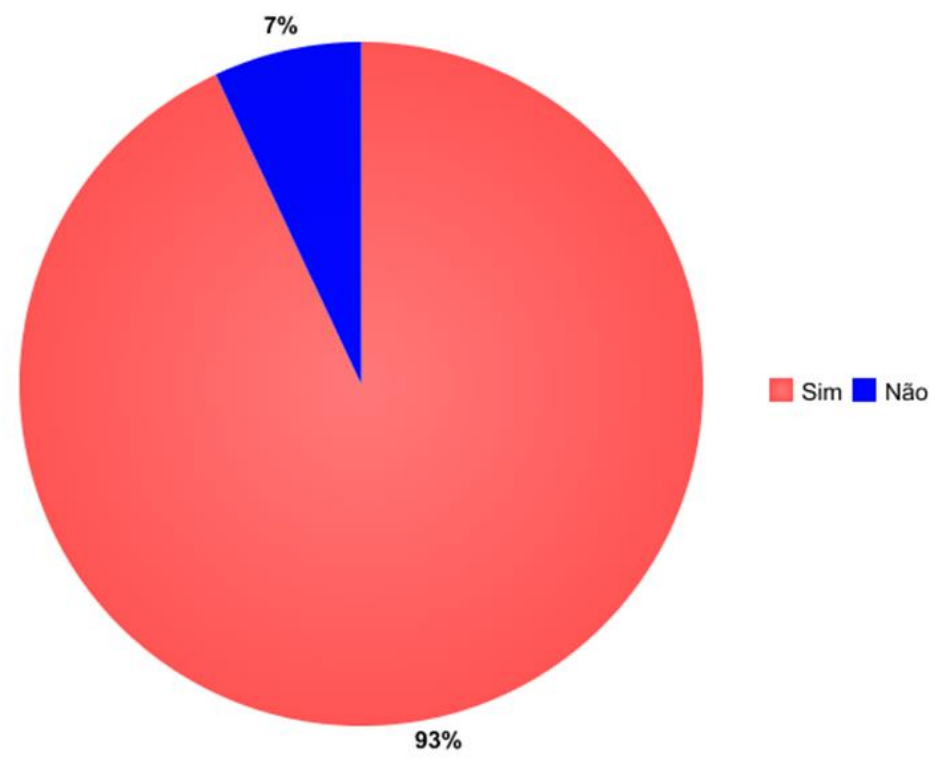

Fonte: os autores.

Apesar de concordarem que é possível ensinar história da Idade Média para crianças e adolescentes, os investigados divergiram quanto à simplicidade ou complexidade desse conteúdo. Os professores que acreditam na facilidade de compreensão apontam para a concepção de que tal temática é simples porque é interessante, atrativa, fascinante, e capaz de despertar a curiosidade dos estudantes, tornando, assim, descomplicado sua assimilação, conforme pode ser verificado nas narrativas dos professores 1, 4, 5, 6 e 9:

Os conteúdos, os conceitos sobre a Idade Média são fáceis e bem definidos, o que torna o conteúdo de fácil compreensão. (PROFESSOR 1). 
São conteúdos fáceis, sem muita complexidade e interessante aos alunos. (PROFESSOR 4).

Nos dias de hoje, a Idade Média exerce uma fascinação irrecusável sobre a imaginação dos alunos, falar da Idade Média e falar de nós mesmos. (PROFESSOR 5).

[...] É um mundo de curiosidade, podemos levar os alunos ao mundo da imaginação [...]. (PROFESSOR 6).

A Idade medieval possui conteúdo bem atrativo que desperta a curiosidade tornando-o de fácil compreensão. (PROFESSOR 9).

Os professores que acreditam na complexidade dos conteúdos da História Medieval se esbarram em um ponto comum, pois chamam a responsabilidade do ensino para si, acreditando que a aprendizagem dos alunos depende de uma aula bem planejada, ministrada de forma interessante e, acima de tudo, contextualizada. Esta inferência é encontrada nos argumentos narrativos dos professores 2, 3, 6, 10 e 12:

Alguns conteúdos são complexos, mas com uma boa aula, com pesquisas, eles compreendem. (PROFESSOR 2).

Os conteúdos sobre a Idade Média são complexos, mais se trabalhar de forma correta, com uma boa aula ministrada pode ser interessante fazendo com que os alunos compreendem os conteúdos. (PROFESSOR 3).

Acredito que os conteúdos sobre Idade Média são realmente complexos para serem ministrados no Ensino Fundamental II, porém se trabalhados de forma contextualizada pode ser interessante. (PROFESSOR 6).

Cabe ao educador usar todos os recursos para que desperte no aluno o interessante e o entendimento do conteúdo. (PROFESSOR 10).

Cabe ao professor usar suas estratégias e recursos pedagogicamente para despertar nos alunos o interesse e seu entendimento da disciplina. (PROFESSOR 12).

O único que não acredita ser possível a assimilação da medievalidade é o Professor 7, o qual declarou que os estudantes "são imaturos e o conteúdo é bem distante da realidade sendo difícil torná-lo significativo". Um dado importante a salientar é o fato em que as pesquisas europeias da Educação Histórica concluíram que estudantes mais jovens são capazes de fazer 
inferências mais complexas do que estudantes com mais idade escolar, demonstrando, assim, que qualquer conhecimento sobre o passado, por mais abstrato que possa ser, pode, e deve ser ensinado como História para o Ensino Fundamental (BARCA, 2004). Já existem pesquisas no Brasil que indicam as crianças dos anos iniciais do Ensino Fundamental como capazes de assimilar o deslocamento temporal, e de que elas aceitam os conteúdos do livro didático como verdadeiros (TUMA; CAINELLI; OLIVEIRA, 2010).

As investigações em Educação Histórica confirmam que os conteúdos são assimiláveis pelos estudantes, isto mostra que os temas referentes à Idade Média por mais abstratos que sejam, são compreensíveis e capazes de serem relacionados à realidade atual de crianças e jovens, pois estão presentes e são evocados na atualidade por meio da indústria cultural.

\section{Considerações finais}

Tendo em vista o estudo realizado, observa-se que a Idade Média se configura como conceito, como conteúdo e como um período histórico que é valorizado pelo currículo de História da escola básica no Brasil servindo, assim, para esclarecer os processos que possibilitam a compreensão das mudanças e permanências ocorridas no tempo. Por isso, é imprescindível que historiadores e professores se dediquem a pesquisas e reflexões para tornar possível o ensino dessa temática na educação básica.

Conforme exposto nesta pesquisa, há uma variedade ou multiplicidade de concepções sobre a História Medieval, as quais são transmitidas pelos professores aos seus alunos no cotidiano escolar. Essas interpretações afetam diretamente a construção das ideias históricas dos estudantes. É de grande importância que os alunos dos anos finais do Ensino Fundamental, da educação brasileira, sejam provocados, ou despertados, nessa faixa etária, para que tenham uma visão crítica, e talvez otimista, do período em questão. A historiografia superou desde o século XIX a imagem negativa e inferiorizada da Idade Média (como foi observado, e discutido, no texto), pois este período contribuiu para construção da modernidade e, consequentemente, para 
construção do mundo ocidental. Por essa razão não deve ser desprezado porque auxilia no entendimento, ou compreensão, do mundo atual.

Os dados obtidos a partir do grupo participante permitiram a classificação das narrativas em tradicional, evasiva, pessimista e otimista. Sendo assim, os professores demonstraram que além do livro didático ser utilizado para o ensino do período medieval, possuem uma predileção pelos recursos midiáticos como os vídeos, filmes e documentários, o que não significa que um ou outro não faça uso de outro elemento em suas aulas. Os assuntos da Idade Média que os profissionais da educação mais citaram foram o feudalismo, as Cruzadas e a Peste Negra. Em sua maioria concordaram que os estudantes dessa fase da educação básica são capazes de compreender a Idade Média, só divergiram quanto à complexidade ou inteligibilidade do conteúdo.

Os professores, na sua maioria, admitiram a importância do período medieval e demonstraram a possibilidade de sua compreensão por parte dos alunos dos anos finais do Ensino Fundamental. Dito isso, sugere-se que os recursos midiáticos, as linguagens, as novas tecnologias e o livro didático, mencionados na pesquisa, possam auxiliar o ensino da disciplina de História na tentativa de superar as visões tradicionais, pessimistas e evasivas dos conteúdos que, por seu caráter abstrato, se mostram distantes da realidade e da vida prática dos escolares, cabendo ao professor torná-los significativos e assimiláveis. Ressalta-se, ainda, que os recursos mencionados possam iluminar a imaginação para que os estudantes alcancem um conhecimento real dos processos históricos, com suas mudanças e permanências, uma vez que a Idade Média continuará presente na sociedade contemporânea.

No que se refere aos professores, é pertinente, e necessária, a formação continuada. A superação, ou a mudança, de visões e percepções sobre determinados conteúdos históricos que estão sendo atualizados pelas pesquisas historiográficas, precisam chegar até a educação básica. O livro didático já vem apresentando incorporação das recentes pesquisas, porém sozinho não resolve o problema dessa defasagem. Dessa forma, a universidade e as esferas municipais e estaduais precisam buscar parcerias para alavancar esse tipo de formação, assim os professores se manterão em constante reflexão para construção de 
suas visões e percepções sobre os conteúdos do currículo básico adotado no Brasil.

\section{Referências}

BARCA, Isabel. A educação histórica numa sociedade aberta. Currículo sem Fronteiras, v.7, n.1, p. 5-9, jan./jun., 2007a.

BARCA, Isabel. Concepções de adolescentes sobre múltiplas explicações em História. In: JORNADAS INTERNACIONAIS DE EDUCAÇÃO HISTÓRICA, 1., 2000, Braga. Actas... Braga: Instituto de Educação e Psicologia, Universidade do Minho, Portugal, 2000a. p. 29-36.

BARCA, Isabel. Educação Histórica: uma nova área de investigação. Revista da Faculdade de Letras, Porto, III Série, v. 2, p. 13-2, 2011.

BARCA, Isabel. Ideias chaves para a Educação Histórica: uma busca de (inter)identidades. História Regional, Goiânia, v. 17, n. 1, p. 37-51, jan./jun. 2012.

BARCA, Isabel. Literacia e consciência histórica. Educar em Revista, Curitiba, n. esp., p. 93-112, 2006.

BARCA, Isabel. Marcos de consciência histórica de jovens portugueses. Currículo Sem Fronteiras, v.7, n.1, p.115-126, jan./jun., 2007b.

BARCA, Isabel. O pensamento histórico dos jovens: ideias dos adolescentes acerca da provisoriedade da explicação histórica. Braga: Lusografe, 2000b.

BARCA, Isabel. Os jovens portugueses: ideias em História. Perspectiva, Florianópolis, v. 22, n. 2, p. 381-403, jul./dez. 2004.

BARCA, Isabel; GAGO, Marília. Aprender a pensar em história: um estudo com alunos do $6^{\circ}$ ano de escolaridade. Revista Portuguesa de Educação, Braga, v. 14, n. 1 , p. $239-261,2001$.

BLOCH, Marc. Apologia da história ou o ofício do historiador. Rio de Janeiro: Jorge Zahar Editor, 2001.

CAINELLI, Marlene Rosa. A construção do pensamento histórico em aulas de História no Ensino Fundamental. Tempos Históricos, Cascavel, v. 12, 10 sem., p. 97-109, 2008.

CAINELLI, Marlene Rosa. A escrita da história e os conteúdos ensinados na disciplina de História no Ensino Fundamental. Educação e Filosofia, Uberlândia, v. 26, n. 51, p. 163-184, jan./jun. 2012. 
CAINELLI, Marlene Rosa; SCHMIDT, Maria Auxiliadora. Desafios teóricos e epistemológicos na pesquisa em educação histórica. Antíteses, Londrina, v. 5, n. 10, p. 509-518, jul./dez. 2012.

CAINELLI, Marlene Rosa; TUMA, Magda Madalena P. História e memória na construção do pensamento histórico: uma investigação em educação histórica. Revista HISTEDBR On-line, Campinas, n. 34, p. 211-222, jun., 2009.

CASTEX, Lilian Costa. O conceito substantivo Ditadura Militar Brasileira (19641984) na perspectiva de jovens brasileiros: um estudo de caso em escolas de Curitiba - PR. 2008. Dissertação (Mestrado em História) - Universidade Federal do Paraná, Curitiba, 2008.

GERMINARI, Geyso D. Educação Histórica: a constituição de um campo de pesquisa. Revista HISTEDBR On-line, Campinas, v. 11, n.42, p. 54-70, jun./2011.

MORAES, Rodrigo. O plágio na pesquisa acadêmica: a proliferação da desonestidade intelectual. Diálogos Possíveis, Salvador, v. 3, n. 1, p. 91-109, jan./jun, 2004.

PINA, Max Lanio Martins. A educação histórica como linha de investigação inovadora para o ensino de história. Revista Eletrônica História em Reflexão, Dourados, v. 10, n. 19, p. 152-168, jan/jun., $2016 a$.

PINA, Max Lanio Martins. "Como treinar o seu dragão": a cultura histórica em torno da Idade Média e a polêmica gerada pela BNCC. In: BUENO, André; ESTACHESKI, Dulceli; CREMA, Everton (Org.). Para um novo amanhã: visões sobre aprendizagem histórica. Rio de Janeiro, União da Vitória: Edição LAPHIS, Sobre Ontens, 2016b.

RÜSEN, Jörn. Conceitos históricos. In: - Reconstrução do passado: teoria da História II - os princípios da pesquisa histórica. Brasília: Editora da UnB, 2007. p. 91-100.

RÜSEN, Jörn. Razão histórica - Teoria da História: fundamentos da ciência histórica. Traduçao Estevão de Rezende Martins. Brasília: Ed. UnB, 2001.

SADDI, Rafael. Educação histórica como Meta-hermenêutica. In: BARCA, Isabel. Consciência Histórica na Era da Globalização. Atas das XI Jornadas Internacionais de Educação Histórica. Realizadas de 15 a 18 de Julho de 2011, Instituto de Educação da Universidade do Minho/Museu D. Diogo de Sousa, Braga/Pt.

SANCHES, Tiago Costa; SCHMIDT, Maria Auxiliadora. Educação Histórica no Ensino Fundamental: reflexões teórico-metodológicas a partir do uso de fontes históricas em sala de aula. Revista de Educação Histórica, Curitiba, n. 2, p. 5361, Dez. 2102 - Abr. 2013.

SILVA, Maria da Conceição. Educação Histórica: a temática religião na formação da consciência histórica de alunos brasileiros e portugueses. Revista OPSIS, Catalão-GO, v. 14, n. 2, p. 77-93, jul./dez. 2014. 
SILVA, Maria da Conceição. Educação Histórica: perspectivas para o ensino de história em Goiás. SÆculum - Revista de História, João Pessoa, n. 24, p. 197211, jan./ jun. 2011.

SILVA, Maria da Conceição. Investigação em Educação Histórica: análises da temática religião em textos didáticos de História. Educar em Revista, Curitiba, n. 45, p. 259-272, jul./set. 2012.

TUMA, Magda Madalena; CAINELLI, Marlene Rosa; OLIVEIRA, Sandra Regina Ferreira de. Os deslocamentos temporais e a aprendizagem da história nos anos iniciais do ensino fundamental. Caderno Cedes, Campinas, v. 30, n. 82, p. 355367, set.-dez. 2010. 